\title{
PENINGKATAN PEMAHAMAN DONGENG ANAK TUNARUNGU MELALUI SIMULATION BASED LEARNING
}

\author{
Endang Sri Handayani, Priyono, Mohammad Anwar \\ Universitas Sebelas Maret \\ endangshandayani@gmail.com
}

\begin{abstract}
The research aims to determine the influence of application simulation based learning toward understanding of fairy tale for children with hearing impairment in third grade at SLB-B YRTRW Surakarta 2016/2017 academic year. This research uses a quantitative approach to research methods of experimental type of pre-experimental form one group pretest-posttest design. Subjek in this research were students in third grade at SLB-B YRTRW Surakarta 2016/2017 academic year as many as four students. Data collection techniques in this research is an objective test in multiple choice. Data analysis techniques in this research is the analysis of non-parametric Wilcoxon Signed Rank test (Wilcoxon Signed Rank Test) using SPSS versi 22. From the result of calculations using SPSS versi 22, the known value of the average posttest research sample increased. Descriptive analysis result obtained by the average value of 77,5 posttest greater than the value pretest 57,5. Non-parametric analysis result obtained count value $Z=-2,000$ with Asymp. Sig. (2-tailed) =0,046 at significance level $(\alpha)$ of 5\%. Based on the results of data analysis can be concluded that effect of application simulation based learning is positive toward understanding of fairy tale for children with hearing impairment in thirdgradeatSLB-B YRTRW Surakarta 2016/2017academic year.
\end{abstract}

Keywords: Simulation Based Learning, understanding of fairy tales, children with hearing impairment

\section{A. PENDAHULUAN}

Anak Berkebutuhan Khusus (ABK) adalah individu yang kehilangan atau mengalami penurunan fungsi indera yang berdampak terhadap masalah belajar atau masalah tingkah laku, dan yang mempunyai keistimewaan intelektual sehingga membutuhkan layanan pendidikan khusus untuk mengembangkan potensi yang masih dan/atau sudah dimiliki. Berdasarkan Undang - Undang Sistem Pendidikan Nasional no 20 tahun 2003 tentang pendidikan khusus dan pendidikan layanan khusus pasal 32 Ayat (1) "Pendidikan khusus merupakan pendidikan bagi peserta didikyang memiliki tingkat kesulitan dalam mengikuti proses pembelajaran karena kelainan fisik, emosional, mental, sosial, dan/atau memiliki potensi kecerdasan dan bakat istimewa."

ABK dengan kelainan fisik yang membutuhkan layanan pendidikan khusus salah satunya adalah anak tunarungu. Tunarungu merupakan kelainan pada indera pendengaran. Haenudin (2013:56) mendefinisikan tunarungu adalah Seseorang yang mengalami kekurangan atau kehilangan kemampuan mendengar baik sebagian atau seluruhnya yang diakibatkan karena tidak berfungsinya sebagian atau seluruh alat pendengaran, sehingga ia tidak dapat menggunakan alat pendengarannya dalam kehidupan seharihari yang membawa dampak dalam kehidupansecara kompleks.

Anak tunarungu pada umumnya memiliki karakteristik secara fisik seperti anak normal. Kemampuan intelegensi anak tunarungu sama seperti anak normal, namun karena keterbatasan informasi yang diterima melalui indera pendengaran menyebabkan perkembangan intelegensinya terlambat. Perkembangan bahasa anak tunarungu juga mengalami hambatan. "Bahasa dan 
bicara merupakan hasil proses peniruan, sehingga tunarungu dalam segi bahasa memiliki ciri yang khas, yaitu sangat terbatasdalam penguasaan kosa kata, sulit mengartikan arti kiasan dan kata - kata yang bersifat abstrak" (Haenudin, 2013:67). Untuk memahami sesuatu yang terjadi disekitarnya, anak tunarungu bergantung pada indera penglihatannya. Sehingga anak tunarungu sering disebut sebagai "pemata" karena mereka kurang bisa memvisualisasikan konsep yang diberikan secara verbal dan pengamatan mereka tertumpu pada indera penglihatan (Wardani, dkk, 2011:5. 20).

Hambatan - hambatan yang dialami anak tunarungu tersebut menyebabkan prestasi belajar rendah. Wulandari, A A., dkk (2014) menemukan nilai rata - rata matematika siswa tunarungu adalah 55 (skala 0-100). Prestasi belajar anak tunarungu yang rendah karena minimnya informasi yang diterima melalui indera pendengarannya berdampak juga pada kemampuan daya abstraksi yang rendah. Anak tunarungu sulit menerima konsep baru yang bersifat abstrak, sehingga anak tunarungu membutuhkan gambaran yang jelas dan rinci agar dapat memahami konsep yang baru.

Pembelajaran Bahasa Indonesia di Sekolah Luar Biasa (SLB) terdapat beberapa materi yang melibatkan kemampuan pemahaman. Materi - materi tersebut meliputi dongeng, cerita pendek, puisi dan komik. Selanjutnya, dongeng merupakan materi cerita yang paling digemari anak karena dongeng berisi cerita - cerita yang sederhana tetapi menarik. Dongeng adalah cerita yang tidak benar - benar terjadi. Dongeng diceritakan sebagai hiburan walaupun banyak juga melukiskan kebenaran, berisikan pelajaran moral dan bahkan sindiran yang tertulis secara tersurat maupun tersirat. Dengan mengetahui dan memahami isi dongeng diharapkan anak dapat mengembangkan daya imajinasi, wawasan, dan juga kreativitasnya. Anak tunarungu juga menggemari dongeng yang disampaikan oleh pendidik. Namun, anak tunarungu sering mengalami kesalahan dalam memahami maksud, isi, tujuan serta alur dongeng.

\section{B. KAJIAN LITERATUR}

Metode pembelajaran sangat beragam sehingga pendidik harus dapat memilih metode yang tepat dan sesuai dengan tujuan pembelajaran dan kondisi anak. Salah satu alternatif metode yang dapat digunakan dalam pembelajaran pemahaman dongeng bagi anak tunarungu adalah Simulation Based Learning. "Simulation Based Learning merupakan strategi pembelajaran yang memiliki karakteristik yaitu peserta didik diminta untuk mengalami suatu peristiwa yang sedang dipelajarinya" (Warsita, 2008:291). Dengan Simulation Based Learning, anak tunarungu diminta untuk mensimulasikan atau memerankan tokoh - tokoh yang ada di dalam dongeng. Rinanda (2013) menemukan bahwa metode simulasi efektif dalam meningkatkan kemampuan mitigasi pada anak tunagrahita ringan (nilai rata rata67,75 dengan skala $0-100$ ).

Tujuan penelitian adalah untuk mengetahui pengaruh penerapan Simulation Based Learning terhadap pemahaman dongeng pada siswa tunarungu kelas III di SLB-B YRTRW Surakarta tahun ajaran 2016/2017.

\section{METODOLOGI PENELITIAN}

Penelitian ini menggunakan pendekatan kuantitatif eksperimen karena bertujuan untuk mengetahui hubungan sebab akibat dari pemberian perlakuan/treatment terhadap subjek penelitian. Desain yang digunakan dalam penelitian adalah PreEksperimental design yang berbentuk One Group Pretest-Posttes Design karena untuk mengetahui kemampuan pemahaman dongeng subjek sebelum dan sesudah diberi perlakuan dengan 
menggunakan Simulation Based Learning.

Penelitian ini dilakukan pada bulan Desember 2016 - April 2017. Subjek dalam penelitian ini adalah anak tunarungu kelas III di SLB - B YRTRW Surakarta Tahun ajaran 2016/2017 yang berjumlah 4 siswa, terdiri dari 3 siswa laki- laki dan 1 siswa perempuan. Penentuan subjek dalam penelitian menggunakan teknik sampling purposive. Sugiyono (2013:124) berpendapat bahwa "sampling purposive adalah teknik penentuan sampel dengan pertimbangan tertentu." Pertimbangan dalam pemilihan subjek penelitian adalah karena anak tunarungu tersebut memiliki kemampuan pemahaman yang rendah terhadap isi teks bacaan, nilai ulangan Bahasa Indonesia anak tunarungu rendah dan anak tunarungu mengalami kesulitan dalam mengerjakan soal yang berkaitan dengan teks bacaan.

Teknik pengumpulan data yang digunakan dalam penelitian adalah tes. Penggunaan tes bertujuan untuk mengetahui sejauhmana kemampuan pemahaman dongeng anak tunarungu sebelum dan sesudah menggunakan Simulation Based Learning. Jenis tes yang digunakan dalam penelitian adalah tes tertulis objektif berbentuk pilihan ganda yang berjumlah 10 soal. Hasil dari tes yang berupa nilai atau skor digunakan untuk mengukur tingkat pemahaman dongeng anak tunarungu kelas III di SLB - B YRTRW Surakarta Tahun ajaran 2016/2017 sebelum dan sesudah diberi perlakuan.

Validitas yang digunakan dalam penelitian adalah validitas isi. Azwar mengatakan bahwa "validitas isi merupakan validitas yang diestimasi lewat pengujian terhadap kelayakan atau relevansi isi tes melakukan analisis rasional oleh panel yang berkompeten atau memalui expert judgment" (2012:7-8). Validitas isi ialah derajat dimana sebuah tesmengukur cakupan substansi yang ingin diukur. Untuk menguji validitas instrument terlebih dikonsultasikan dengan ahli, lalu diujicobakan dan dianalisis dengan analisis item atau uji beda. Sedangkan untuk mengetahui reliabilitas tes, peneliti menggunakan rumus Spearman Brown (Split half) dan diolah dengan komputer dengan program SPSS versi 22.

Analisis data yang digunakan adalah analisis statistik non parametrik yaitu analisis tes rangking bertanda (Wilcoxon Sign Rank Test) yang diberi tanda $\mathrm{Z}$ dan diolah dengan aplikasi program SPSS versi 22.

\section{HASIL DAN PEMBAHASAN}

Hasil penelitian meliputi data nilai pretes dan postes subjek pada kegiatan yang telah dilaksanakan selama penelitian. Diperoleh data nilai pretes sebagai berikut:

Tabel 1

Data Statistik Nilai Postes

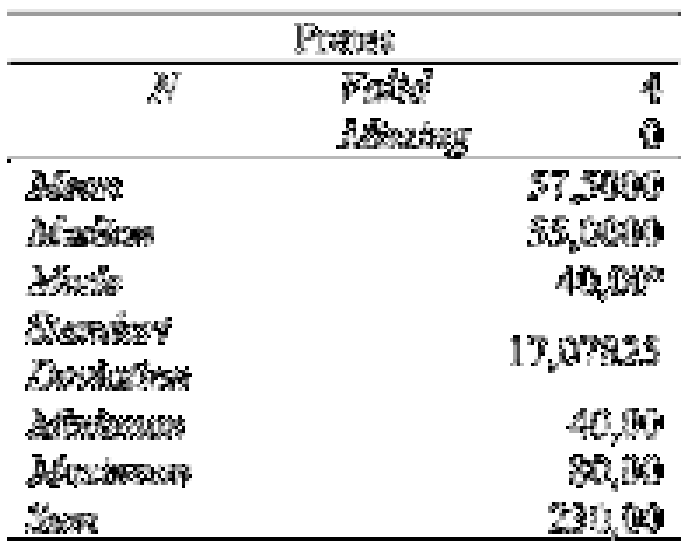

Data deskripsi statistik nilai pretes menunjukkan rata-rata nilai (mean) adalah 57,5000; dengan nilai tertinggi yaitu 80,00 dan nilai terendah yaitu 40,00; sedangkan nilai tengah (median) adalah 55,0000 dan simpangan baku (standart deviation) adalah 17,07825. Dari data nilai pretes siswa dapat disajikan dalam bentuk grafik histogram sebagai berikut: 


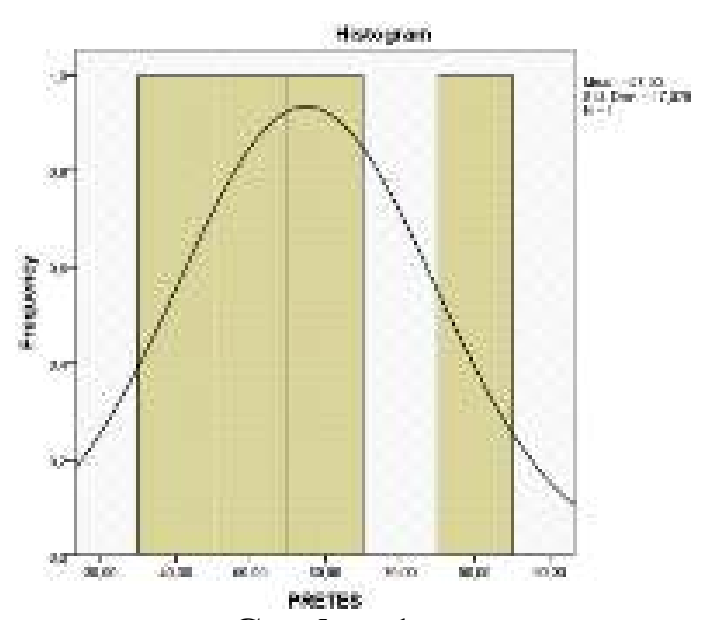

Gambar 1

Grafik Histogram Pretes

Data Kemampuan Siswa Setelah Perlakuan (Postes), diperoleh data nilai sebagai berikut.

Tabel 2

Data Statistik Nilai Postes

\begin{tabular}{|c|c|c|}
\hline \multicolumn{3}{|c|}{ Fowiab } \\
\hline N & 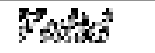 & 4. \\
\hline & Axtoing & 1) \\
\hline 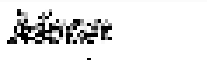 & & $" F, y 0,0,1$ \\
\hline 36roticas & & 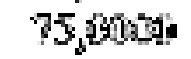 \\
\hline xosy & & 6Q \\
\hline 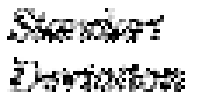 & & $17,678+3$ \\
\hline gloxkmase & & Geitu \\
\hline 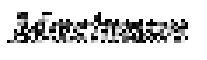 & & 134,60 \\
\hline Sape & & Bluter \\
\hline
\end{tabular}

Data deskripsi statistik nilai postes kemampuan pemahaman dongeng, menunjukkan rata-rata nilai siswa (mean) sebesar 77,5000; dengan nilai tertinggi yaitu 100,00 dan nilai terendah yaitu 60,00 ; sedangkan nilai tengah (median) sebesar 75,0000 dengan simpangan baku (standart deviation) sebesar 17,07825.

Data nilai postes siswa dapat disajikan dalam bentuk grafik histogram sebagai berikut.

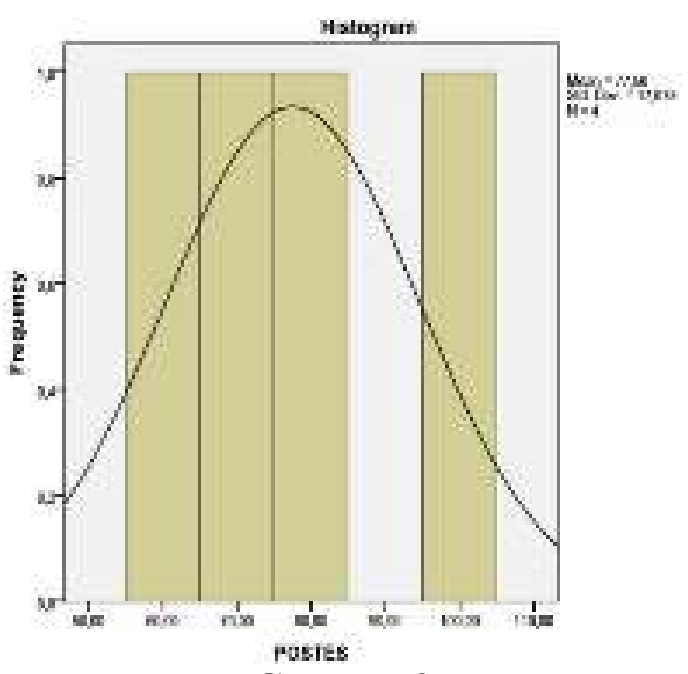

Gambar 2

Grafik Histogram Postes

Data nilai pretes dan postes kemampuan pemahaman dongeng siswa kelas III SLB-B YRTRW Surakarta tahun pelajaran 2016/2017disajikan dalam tabel 3.

\section{Tabel 3}

Deskripsi Statistik Nilai Pretes dan Postes

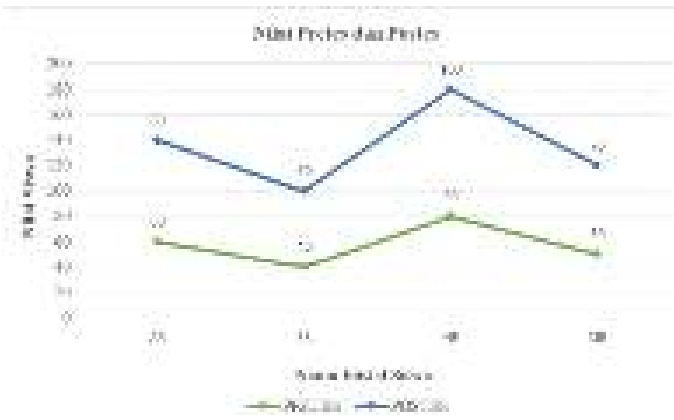

Berdasarkan deskripsi data pada tabel 3, diketahui bahwa nilai rata-rata (mean) kemampuan pemahaman dongeng sebelum menggunakan Simulation Based Learning adalah 57,50; sedangkan nilai rata-rata (mean) setelah menggunakan Simulation Based Learning adalah 77,50. Selisih nilai ratarata (mean) menunjukkan perbedaan kondisi sebelum dan sesudah diberikan perlakuan. Berikut gambar diagram garis dari peningkatan sebelum pemberian treatment (pretes) dengan menggunakan Simulation Based Learning dan sesudah 
pemberian treatment (postes) dengan menggunakan Simulation Based Learning.

Untuk membuktikan hipotesis bahwa Penerapan Simulation Based Learning berpengaruh terhadap peningkatan pemahaman dongeng pada siswa tunarungu kelas III di SLB-B YRTRW Surakarta tahun ajaran 2016/2017 digunakan analisis Wilcoxon Signed Ranks Test dengan bantuan software SPSS versi 22.

Berikut adalah tabel hasil tes statistik analisis Wilcoxon Sign Rank Test yang diperoleh dari perhitungan menggunakan software SPSS 22 pada tabel 4.

Tabel 4

Hasil Tes Statistik

\begin{tabular}{|c|c|}
\hline & $t^{\prime \prime a s t i z e t}$ \\
\hline E' & \\
\hline
\end{tabular}

Tabel 4 menunjukkan nilai Wilcoxon Signed Ranks Test Zhitung= -2,000 dan Asymp. Sig. (2-tailed) $=0,046$ dengan taraf signifikansi $(\alpha)$ 5\%. Nilai Asymp Sig (2tailed $)=0,046$ kurang dari taraf signifikansi $(\alpha)=0,05(0,046<0,05)$ maka hipotesis nihil (Ho) ditolak dan hipotesis kerja (Ha) diterima. Jadi dapat disimpulkan bahwa penerapan Simulation Based Learning berpengaruh secara signifikan terhadap peningkatan pemahaman dongeng pada siswa tunarungu kelas III di SLB-B YRTRW Surakarta tahun ajaran2016/2017.

Berdasarkan hasil penelitian terdapat peningkatan antara nilai rata - rata sebelum diberi perlakuan (pretes) dengan menggunakan Simulation Based Learning yaitu 57,50 dan nilai setelah diberi perlakuan (postes) dengan menggunakan Simulation Based Learning yaitu 77,50. Simulation Based Learning merupakan salah satu pembelajaran yang melibatkan siswa secara langsung sebagai simulator, siswa berperan atau mengalami peristiwa sesuai dengan materi pembelajaran yang sedang dipelajari. Dalam penelitian ini, siswa melakukan simulasi tentang dongeng Timun Emas. Kegiatan yang dilakukan dengan Simulation Based Learning pertama dimulai dengan memberikan penjelasan tentang pembelajaran dongeng dengan menggunakan Simulation Based Learning. Tujuan pemberian penjelasan ini adalah agar siswa mengetahui tentang Simulation Based Learning dan cara menggunakannya. Kedua, siswa membaca dongeng yang akan disimulasikan dan mempelajari lebih dalam tentang perannya. Siswa membaca dan memahami perannya agar saat pelaksanaan simulasi bisa berjalan lancar. Ketiga, sebelum siswa melakukan simulasi, siswa diperlihatkan video yang sesuai dengan dongeng yang akan disimulasikan dengan tujuan untuk menarik perhatian siswa dan memberi gambaran yang lebih jelas tentang pelaksanaan Simulation Based Learning. Siswa yang memiliki ketertarikan terhadap pembelajaran akan lebih mudah memahami isi materi. Keempat, siswa melakukan simulasi agar lebih memahami maksud dari isi dongeng. Kelima, setelah siswa melakukan simulasi kemudian siswa menjawab pertanyaan yang berkaitan dengan isi dongeng untuk mengukur tingkat pemahaman siswa dan yang terakhir siswa bersama peneliti membahas dan mengevaluasi apa yang sudah dilakukan siswa.

Siswa yang sebelumnya belum mengenal Simulation Based Learning pada awal pertemuan mengalami kesulitan dalam melakukan simulasi tetapi lama - kelamaan siswa terbiasa melakukan pembelajaran dengan menggunakan Simulation Based Learning. Simulation Based Learning berpengaruh terhadap peningkatan pemahaman dongeng anak tunarungu karena melalui Simulation Based Learning anak melakukan sendiri secara langsung dongeng yang sedang dipelajari. Anak tunarungu memiliki daya abstraksi yang rendah sehingga menyebabkan kesulitan dalam memahami isi dongeng, tetapi dengan melakukan sendiri dan memerankan 
tokoh atau karakter yang ada dalam dongeng membuat anak menjadi lebih mudah dalam memahami isi dongeng karena anak memiliki gambaran secara langsung. Selain itu, dengan melakukan secara langsung, anak menjadi lebih aktif karena pembelajaran tidak monoton hanya duduk di kelas memperhatikan guru tetapi anak mempunyai kesempatan untuk bertanya, berdiskusi dan berpendapat sehingga pembelajaran menjadi lebih bermakna. Penelitian Auerbach (2013) yang berjudul "United States Supreme Court Confirmation Simulation: Learning through the Process of Experience" menemukan bahwa dengan simulasi dapat meningkatkan keaktifan mahasiswa dalam pembelajaran.

Keaktifan siswa dalam proses pembelajaran akan menciptakan suasana belajar yang menyenangkan sehingga tujuan pembelajaran dapat tercapai secara maksimal. Hal ini selaras dengan penelitian yang dilakukan Hidayat \& Rejeki (2015) yang berjudul "Upaya Meningkatkan Prestasi Belajar Pendidikan Kewarganegaraan Dengan Metode Simulasi Pada Siswa Kelas VA SD Negeri Tegalrejo 1 Yogyakarta" menemukan bahwa Penerapan metode simulasi dapat meningkatkan proses pembelajaran Pendidikan Kewarganegaraan Pada Siswa Kelas VA SD Negeri Tegalrejo 1 Yogyakarta. Penelitian Wedig (2010) dengan judul "Getting the Most from Classroom Simulations: Strategies for Maximizing Learning Outcomes" menemukan bahwa simulasi secara signifikan dapat meningkatkan hasil belajar siswa dalam pembelajaran ilmu politik.

Peningkatan pemahaman dongeng anak tunarungu melalui Simulation Based Learning juga disebabkan karena motivasi anak yang tinggi sehingga menimbulkan rasa ingin tahu dan ketertarikan terhadap dongeng yang sedang dipelajari. Penelitian Sunaryo (2015) berjudul "Pengaruh Metode Simulasi Dan Motivasi Belajar Siswa Terhadap Prestasi Belajar Ilmu Pengetahuan Sosial Kelas IV SD Negeri 2 Lugosobo Gerbang Purworejo Tahun Pelajaran
2011/2012" menemukan bahwa siswa yang memiliki motivasi tinggi dan diberi pelajaran dengan metode simulasi memiliki prestasi belajar yang lebih baik dibandingkan siswa yang memiliki motivasi tinggi dan diberi pelajaran dengan metode konvensional.

Anak tunarungu merupakan anak yang lebih mengandalkan indera penglihatannya untuk memahami sesuatu, hal ini sesuai dengan pendapat Haenudin (2013:66) yang mengatakan bahwa anak tunarungu sering disebut sebagai "insan pemata" karena anak tunarungu lebih banyak memehami sesuatu dari apa yang mereka lihat, bukan dari apa yang mereka dengar. Dengan melihat video tentang dongeng dan melihat pelaksanaan simulasi tentang dongeng membuat anak lebih mudah memahami isi dongeng.

Penggunaan Simulation Based Learning pada mata pelajaran Bahasa Indonesia materi dongeng sangat diperlukan bagi anak tunarungu. Anak tunarungu merupakan seseorang yang kehilangan kemampuan mendengar baik sebagian atau seluruhnya yang diakibatkan oleh tidak berfungsinya sebagian atau seluruh alat pendengaran sehingga mengalami kesulitan dalam berkomunikasi baik dengan atau tanpa menggunakan alat bantu mendengar. Akibat ketunarunguan yang dialami berdampak pada kehidupan sehari-hari yang kompleks sehingga membutuhkan layanan pendidikan khusus. Akibat gangguan pendengaran yang dialami, anak tunarungu bergantung pada indera penglihatannya untuk memahami lingkungan sekitar. Penggunaan Simulation Based Learning dapat membantu anak tunarungu untuk memahami dongeng. Simulation Based Learning sesuai untuk anak tunarungu karena membawa situasi nyata ke dalam situasi tiruan dalam kegiatan pembelajaran di kelas sehingga anak akan berperan aktif sebagai simulator dengan memerankan instruksi - instruksi 
yang diberikan guru dan informasi yang diperoleh akan lebih bermakna karena anak melakukannya secara langsung sehingga anak dapat mengemukakan pendapat dan pikirannya yang bisa mempermudah tercapainya tujuan pembelajaran.

Berdasarkan hasil perlakuan yang dilakukan selama penelitian, terdapat beberapa kelebihan Simulation Based Learning. Kelebihan tersebut antara lain yaitu siswa lebih aktif dalam pembelajaran, memiliki motivasi yang tinggi, memiliki rasa ingin tahu yang tinggi, memiliki ketertarikan terhadap pembelajaran dan memudahkan pemahaman siswa terhadap isi dongeng. Berdasarkan teori dan hasil penelitian mengenai Simulation Based Learning yang telah dipaparkan, ditemukan bahwa penerapan Simulation Based Learning untuk anak tunarungu terbukti memberikan pemahaman tentang dongeng karena anak melakukan secara langsung apa yang sedang dipelajari sehingga anak lebih mudah mengerti dan memahami isi dongeng karenaanak mengalaminya sendiri, apalagi anak tunarungu merupakan anak yang lebih mengandalkan visualnya untuk memahami sesuatu. Dengan demikian, berdasarkan hasil analisis maka dapat disimpulkan bahwa penerapan Simulation Based Learning berpengaruh secara signifikan terhadap peningkatan pemahaman dongeng pada siswa tunarungu kelas III di SLB-B YRTRW Surakarta tahun ajaran 2016/2017.

\section{E. SIMPULAN DAN REKOMENDASI}

Berdasarkan pembahasan hasil penelitian maka dapat diambil kesimpulan bahwa penerapan Simulation Based Learning berpengaruh secara signifikan terhadap peningkatan pemahaman dongeng pada siswa tunarungu kelas III di SLB-B YRTRW Surakarta tahun ajaran 2016/2017.

Berdasarkan hasil penelitian, maka peneliti memberikan saran sebagaiberikut:

1. Bagi Siswa

$\begin{array}{ccc}\quad \text { Hendaknya } & \text { siswa } & \text { dapat } \\ \text { menggunakan } & \text { Simulation } & \text { Based } \\ \text { Learning dalam } & \text { pembelajaran } & \text { dengan }\end{array}$

bimbingan guru agar terjadi peningkatan kemampuan pemahaman dongeng.

2. Bagi Peneliti Selanjutnya

Mengingat masih ada kekurangan dalam penerapan Simulation Based Learning, maka perlu adanya perbaikan dalam penelitian selanjutnya.

\section{DAFTAR PUSTAKA}

Azwar, Saifuddin. (2012). Metode Penelitian. Yogyakarta: Pustaka Belajar.

Auerbach, A.H. (2013). United States Supreme Court Confirmation Simulation: Learning through the Process of Experience. PS: Political Science \& Politics, 808812.

Haenudin. (2013). Pendidikan Anak Berkebutuhan Khusus Tunarungu. Jakarta: Luxima Metro Media.

Hidayat, D.D.N. \& Rejeki, Sri. (2015). Upaya Meningkatkan Prestasi Belajar Pendidikan Kewarganegaraan Dengan Metode Simulasi Pada Siswa Kelas VA SD Negeri Tegalrejo 1 Yogyakarta. JURNAL PGSD INDONESIA, 1 (1), 11-18.

Mancoro, Nurliatin. (2015). Peningkatan Kemampuan Berbicara Melalui Dongeng Dalam Pembelajaran Bahasa Indonesia Siswa Kelas I SD Negeri 2 Tatura, Jurnal Kreatif Tadulako Online, 4 (4), 306-314.

Retnaningsih, Eka, Haryati, Nas, Luriawati, Deby. (2014). Peningkatan Menyimak Dongeng Menggunakan Media Audio Dengan Strategi Membangkitkan Rasa Ingin Tahu Pada Siswa Kelas VIIA, Jurnal 
Pendidikan Bahasa dan Sastra Indonesia, 3 (1), 1-7.

Rinanda, Suci. (2013). Pengaruh Metode Simulasi Tanggap Bencana Alam Terhadap Kemampuan Mitigasi Pada Anak Tunagrahita Ringan Di Kelas C/D VI Slb Perwari Padang, EJUPEKhu (JURNAL ILMIAH PENDIDIKAN KHUSUS), 1 (1), $163-173=$.

Rosada, Ulfa Danni. (2016). Memperkuat Karakter Anak Melalui Dongeng Berbasis Media Visual, Jurnal CARE (Children Advisory Research and Education), 4 (1), 42-49

Sugiyono. (2013). Metode Penelitian Kuantitatif Kualitatif dan R\&D. Bandung: Alfabeta Sunaryo. (2015). Pengaruh Metode Simulasi Dan Motivasi Belajar Siswa Terhadap Prestasi Belajar Ilmu Pengetahuan Sosial Kelas IV SD Negeri 2 Lugosobo Gerbang Purworejo Tahun Pelajaran 2011/2012. Jurnal Profesi Pendidik, 2 (1), 35-41.

Wahyuni, Daru. \& Baroroh, Kiromim. (2012). Penerapan Metode Pembelajaran Simulasi Untuk Meningkatkan Aktivitas Dan Prestasi Belajar Ekonomika Mikro, Jurnal Ekonomi \& Pendidikan, 9 (1), 102-122.

Wardani, IG. A. K., dkk. (2011). Pengantar Pendidikan Luar Biasa. Jakarta: Universitas Terbuka.

Warsita, Bambang. (2008). Teknologi Pembelajaran Landasan \& Aplikasinya. Jakarta: RinekaCipta

Wedig, Timothy. (2010). Getting the Most from Classroom Simulations: Strategies for Maximizing Learning Outcomes, PS: Political Science \& Politics, 43 (3), 547-555.

Wulandari, A A., Dafik, Susanto. (2014). Penerapan Pembelajaran
Matematika Realistik dengan Whole Brain Teaching pada Pokok Bahasan Teorema Pythagoras untuk Meningkatkan Hasil Belajar dan Aktivitas Siswa Tunarungu Kelas VIIIB SMPLB Sinar Harapan Probolinggo Tahun Ajaran 2014/2015, JURNAL EDUKASI UNEJ, 1 (2), 4046. 